\title{
"Patient-Related Risk Factors For Superficial Surgical Site Infection And The Correlation To Periprosthetic Joint Infection - A 5year Follow-up Of 1291 Elective Primary Total Joint Arthroplasties"
}

Hannah K Eriksson ( $\nabla$ hannah.eriksson@surgsci.uu.se )

Akademiska sjukhuset https://orcid.org/0000-0002-9990-8275

Stergios Lazarinis

Department of Surgical Sciences/Ortopaedics, Uppsala Univeristy

Research article

Keywords: Periprosthetic joint infection, superficial surgical site infection, total joint arthroplasty, total knee arthroplasty, total hip arthroplasty.

Posted Date: July 15 th, 2020

DOl: https://doi.org/10.21203/rs.3.rs-41920/v1

License: (c) (1) This work is licensed under a Creative Commons Attribution 4.0 International License. Read Full License 


\section{Abstract}

Background: The incidence of superficial surgical site infection (SSSI) may increase the risk of subsequent periprosthetic joint infection (PJI). Optimisation or even avoiding patient-related risk factors for SSSI preoperatively, may decrease the risk of subsequent PJI.

Purpose: To identify patient-related risk factors associated with SSSI and investigate their correlation with the progression of PJI.

Methods: 1,291 primary elective hip and knee prosthesis were included. Patients were personally contacted by a nurse $\geq 3$ month after surgery to answer questions about the postoperative period, including any occurrences of SSSI. The diagnosed PJI was determined by an orthopaedic surgeon together with a specialist in infectious diseases, and all patients with PJI underwent revision surgery. The patient-related risk factors considered relevant were joint, age, sex, American Society of Anesthesiologists classification (ASA), body mass index (BMI), smoking, diabetes and rheumatological disease.

Results: 7,0 \% of included patients developed an SSSI, and 1,9\% a PJI. Factors with a significantly increased adjusted risk ratio for SSSI were; knee surgery 1,9 (95\% Cl: 1,2 - 3,1), age $\geq 65$ years 1,7 (95\% Cl: $1,1-2,8), \mathrm{BMI} \geq 352,3$ (95\% Cl: 1,2 - 4,2) and for PJl; knee surgery 2,6 (95\% Cl: 1,1 - 6,4), ASA-class $\geq 3$ 3,2 (95\% Cl: 1,3 - 7,9), BMI $\geq 35$ 3,0 (95\% Cl: $(1,2-4,2)$ and male gender 3,0 (95\% Cl: $(1,2-7,5)$. Male patients showed a significant risk of developing PJI following SSSI, with a risk ratio of $3,3(95 \% \mathrm{Cl}$ : 1,1 $10,5)$.

Conclusions: Male patients planned for total knee prostheses (TKA) aged 65 or over, with high ASA-class and high BMI should be selected with care due to the increased risk of postoperative infection.

\section{Background}

Infection after total joint arthroplasty (TJA) procedures is a rare but devastating complication associated with increased morbidity and mortality $(1-5)$ and comes with potentially disastrous consequences for the patient and significant expenses for the community (1). Infection after TJA may either be defined as superficial; - a superficial surgical site infection (SSSI) or deep; - periprosthetic joint infection (PJI) with involvement of the prosthesis.

An SSSI can be present with local wound signs such as increased exudate, skin necrosis, dehiscence, and delayed healing (6). The incidence of SSSI following TJA range from 1 to $10 \%(7,8)$ and may increase the risk of subsequent PJI by up to 35-times (9). The frequency of PJI ranges between 1 and $5 \%(10-13)$. Patient-related risk factors such as obesity, RA, smoking, male gender, age, alcohol abuse, American Society of Anesthesiologists (ASA) class $>2$ and DM (14-22) have been already described as risks for PJI. In total hip arthroplasty (THA) procedures performed in Sweden 33\% of patients were $\geq 80$ years old,

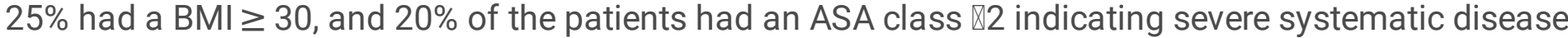
(23). In clinical praxis, the priority should be to first identify those patients who are at high risk for SSSI 
and PJl, aiming for patient optimisation and the opportunity to manage modifiable risk factors, in order to decrease postoperative complications and improve the value of the arthroplasty surgery. An unanswered question with high relevance is which of patient-related factors are associated with the progress of SSSI to PJI.

Our study aims to find a way to preoperatively screen the TJA candidates for the risk of SSSI and PJI by means of (i) elucidate patient-related risk factors associated with the development of SSSI and (ii) clarify patient-related factors associated with the development of PJI in patients with SSSI.

\section{Method}

\section{Study design}

This cross-sectional retrospective study of primary elective prostheses in hip or knee joints included patients in a national project designed to lower the incidence of hospital related infections (24). These patients were personally contacted by a nurse $\geq 3$ months after surgery to answer questions about their postoperative period. The nurse review patients' records to find out if there had been any documentation of difficulties with wound-healing or if antibiotics were prescribed to treat an infection related to the arthroplasty surgery.

The occurrence of SSSI was clinically assessed and verified by a general practitioner or an orthopaedic surgeon, in case of signs for postoperative infection. Whether the patient suffered from a postoperative surgical site infection was always re-evaluated by an orthopaedic surgeon. The occurrence of PJI was determined by an orthopaedic surgeon together with a specialist in infectious diseases. All patients with verified PJI went through revision surgery, combined with antibiotic treatment.

In a retrospective review of patient records, selected patients fulfilled the Musculoskeletal Infection Society (MSIS) criteria for PJI (25), but those criteria had not been used at the time of diagnosis. Patient records were reviewed for patient-related risk factors, and a local arthroplasty register was used to obtain perioperative information about whether revision surgery had been necessary due to persistent PJI.

This study was limited to patient-related risk factors associated with the development of an SSSI and focused on those factors it might be possible to avoid or optimise preoperatively.

The study design was reviewed and approved by the Human Research Ethics Committee (Dnr: 201901425).

\section{Study population}

1,184 patients and 1,314 joints were included in this study. Because of bilateral surgery in the same surgical session were 23 patients excluded, due to an increased risk of infection. In total were 1,291 surgeries (815 hips, 476 knees) included. 
In all knees, only cemented components were used; hip prostheses were cemented, cement-free, or hybrids. In all cemented prostheses, antibiotic-loaded cement with gentamycin was used. All patients received systemic pre- and perioperative antibiotic prophylaxis according to national guidelines (cloxacillin, and in the case of penicillin allergy, clindamycin).

\section{Statistics}

Descriptive statistics were used to summarise and report demographic characteristics.

\section{Confounders}

Patient-related factors considered as relevant confounders in the correlation between arthroplasty surgery and occurrence of SSSI or PJI were joint, sex, age, BMI, RA, ASA class, smoking, and DM.

These specific variables have previously been linked to both exposure and outcome and are not considered to be in the causal pathway between potential risk factors and outcome (Figure 1).

Some of the relevant confounders were analysed as categorical;

- ASA-classification: $<3$ or $\geq 3$

- BMI: $<35$ or $\geq 35$

- Age: $<65$ years or $\geq 65$ years

Patients with diabetes included both type 1 and 2 (drug- or diet-treated). In an initial analysis, logistic regression was performed entering all covariates as singular variables; a crude risk ratio (RR) for SSSI and PJI was calculated for each variable with $95 \%$ confidence interval $(95 \% \mathrm{Cl})$. In the next step, the covariates were entered in the regression model, and RRs were mutually adjusted for all covariates. Adjusted RR for each covariate were calculated for the occurrence of SSSI or PJI.

All statistical analyses were performed using SPSS (version 26.0) and $p$-values $>0.05$ were considered statistically significant.

\section{Results}

In total, 1,291 surgeries of prosthetic hip or knee joints were included. 90 joints (7,0\%) developed an SSSI, and $24(1,9 \%)$ a PJI. Of the 90 joints with SSSI, 24 (26,7\%) progressed to a PJI. In the hip cohort (815), 41 joints (5.0\%) developed an SSSI, and $9(1.1 \%)$ a PJI. In the knee cohort (476), 49 (10,0\%) joints developed an SSSI, and $15(3.2 \%)$ a PJI, Table 1. The demographic characteristics of the cohorts are outlined in Table 2. 
Table 1

Number of postoperative infections

\begin{tabular}{|lll|}
\hline Variable & SSSI & PJI \\
\hline Total cohort (1291) & $90(7 \%)$ & $24(1,9 \%)$ \\
\hline Hip (815) & $41(5 \%)$ & $9(1,1 \%)$ \\
\hline Knee (476) & $49(10 \%)$ & $15(3,2 \%)$ \\
\hline SSSI (superficial surgical site infection), PJI (periprosthetic joint infection). \\
\hline
\end{tabular}


Table 2

Demographic characteristics

\begin{tabular}{|c|c|c|c|c|}
\hline Variable & Total cohort & Hip cohort & Knee cohort & Range \\
\hline & $n=1291$ & $n=815(63 \%)$ & $\mathrm{n}=476(37 \%)$ & \\
\hline Mean age (year) & 63 & 61 & 65 & $18-96$ \\
\hline \multicolumn{5}{|l|}{ Age } \\
\hline$<65$ & $729(56 \%)$ & $479(59 \%)$ & $250(53 \%)$ & \\
\hline$\geq 65$ & $562(44 \%)$ & $336(41 \%)$ & $226(47 \%)$ & \\
\hline \multicolumn{5}{|l|}{ ASA-class $^{a}$} \\
\hline$\leq 2$ & $1048(82 \%)$ & $679(85 \%)$ & $369(79 \%)$ & \\
\hline$\geq 3$ & $225(18 \%)$ & $125(15 \%)$ & $100(21 \%)$ & \\
\hline Mean Body mass index & 28 & 27 & 29 & $14-51$ \\
\hline \multicolumn{5}{|l|}{$\mathrm{BMI}^{\mathrm{b}}$} \\
\hline$<35$ & $1145(90 \%)$ & $743(92 \%)$ & $402(86 \%)$ & \\
\hline$\geq 35$ & $130(10 \%)$ & $63(8 \%)$ & $67(14 \%)$ & \\
\hline \multicolumn{5}{|l|}{ Gender } \\
\hline Woman & $731(57 \%)$ & $421(52 \%)$ & $310(65 \%)$ & \\
\hline Man & $560(43 \%)$ & $394(48 \%)$ & $166(35 \%)$ & \\
\hline \multicolumn{5}{|l|}{ Smoking ${ }^{c}$} \\
\hline No & 1141 (90\%) & $716(90 \%)$ & $425(90 \%)$ & \\
\hline Yes & $129(10 \%)$ & $84(10 \%)$ & $45(10 \%)$ & \\
\hline \multicolumn{5}{|l|}{ Diabetes $^{a}$} \\
\hline No & $1145(90 \%)$ & $731(91 \%)$ & $414(88 \%)$ & \\
\hline
\end{tabular}

ASA (American Society of Anaesthesiologists), BMI (Body mass index).

${ }^{a}$ missing data in 18 cases

${ }^{\mathrm{b}}$ missing data in 16 cases

${ }^{\mathrm{c}}$ missing data in 21 cases

${ }^{d}$ missing data in 100 cases 


\begin{tabular}{|c|c|c|c|c|}
\hline Variable & Total cohort & Hip cohort & Knee cohort & Range \\
\hline Yes & $128(10 \%)$ & $73(9 \%)$ & $55(12 \%)$ & \\
\hline \multicolumn{5}{|l|}{ Rheumatological disease ${ }^{d}$} \\
\hline No & $1052(88 \%)$ & $689(91 \%)$ & $363(83 \%)$ & \\
\hline Yes & $139(12 \%)$ & $67(9 \%)$ & $72(17 \%)$ & \\
\hline \multicolumn{5}{|c|}{ ASA (American Society of Anaesthesiologists), BMI (Body mass index). } \\
\hline \multicolumn{5}{|l|}{${ }^{a}$ missing data in 18 cases } \\
\hline \multicolumn{5}{|l|}{ b missing data in 16 cases } \\
\hline \multicolumn{5}{|l|}{${ }^{\mathrm{C}}$ missing data in 21 cases } \\
\hline${ }^{d}$ missing data in 100 cases & & & & \\
\hline
\end{tabular}

\section{Risk factors for SSSI}

Risk factors with a significant crude RR for development of SSSI were; knee surgery 2,2 (95\% Cl: 1,4-3,3), age $\geq 65$ years 1,7 (95\% Cl: 1,1-2,6), ASA-class $\geq 32,3$ (95\% Cl: 1,4-3,7), BMI $\geq 352,4$ (95\% Cl: 1,4-4,2) and rheumatological disease $1,9(95 \% \mathrm{Cl}: 1,1-3,4)$. When adjusted for all covariates the factors found with significant adjusted RR for SSSI were; knee surgery $1,9(95 \% \mathrm{Cl} 1,2-3,1)$, age $\geq 65$ years 1,7 (95\% Cl: $1,1-2,8)$ and $\mathrm{BMI} \geq 352,3$ (95\% Cl: 1,2-4,2) (Table 3). 
Table 3

Risk ratio (RR) for SSSI

\begin{tabular}{|c|c|c|c|c|c|}
\hline No SSSI & 1201 (93\%) & & & & \\
\hline SSSI & $90(7 \%)$ & & & & \\
\hline \multirow[t]{2}{*}{ Variable } & SSSI & Crude RR & P-value & Adjusted RR & P-value \\
\hline & & $(95 \% \mathrm{Cl})$ & & $(95 \% \mathrm{Cl})$ & \\
\hline \multicolumn{6}{|l|}{ Joint } \\
\hline Hip & $41(45 \%)$ & & & & \\
\hline Knee & $49(55 \%)$ & $2,2(1,4-3,3)$ & 0,000 & $1,9(1,2-3,1)$ & 0.005 \\
\hline \multicolumn{6}{|l|}{ Age } \\
\hline$<65$ & $40(44 \%)$ & & & & \\
\hline$\geq 65$ & $50(56 \%)$ & $1,7(1,1-2,6)$ & 0,018 & $1,7(1,1-2,8)$ & 0,024 \\
\hline \multicolumn{6}{|c|}{ 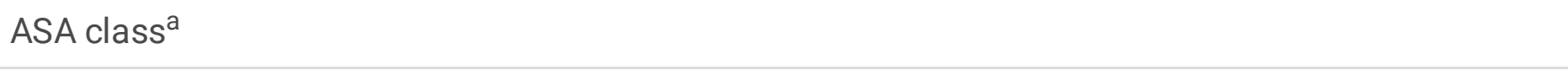 } \\
\hline$\leq 2$ & 61 (69\%) & & & & \\
\hline$\geq 3$ & $28(31 \%)$ & $2,3(1,4-3,7)$ & 0,001 & $1,6(0,9-2,7)$ & 0,069 \\
\hline \multicolumn{6}{|c|}{ Body mass index } \\
\hline$<35$ & 72 (80\%) & & & & \\
\hline$\geq 35$ & $18(20 \%)$ & $2,4(1,4-4,2)$ & 0,002 & $2,3(1,2-4,2)$ & 0,010 \\
\hline \multicolumn{6}{|l|}{ Gender } \\
\hline Woman & 49 (54\%) & & & & \\
\hline Men & $41(46 \%)$ & $1,1(0,7-1,7)$ & 0,666 & $1,4(0,9-2,2)$ & 0,206 \\
\hline \multicolumn{6}{|l|}{ Smoking ${ }^{a}$} \\
\hline No & $80(90 \%)$ & & & & \\
\hline Yes & $9(10 \%)$ & $1,0(0,5-2,0)$ & 0,988 & $1,1(0,5-2,4)$ & 0,836 \\
\hline
\end{tabular}

SSSI (superficial surgical site infection), ASA (American Society of Anaesthesiologists), $\mathrm{Cl}$ (confidence interval)

a missing data in 1 case

${ }^{b}$ missing data in 6 cases 


\begin{tabular}{|c|c|c|c|c|c|}
\hline No SSSI & $1201(93 \%)$ & & & & \\
\hline No & $76(85 \%)$ & & & & \\
\hline Yes & $13(15 \%)$ & $1,6(0,9-3,0)$ & 0,142 & $1,2(0,6-2,3)$ & 0,606 \\
\hline \multicolumn{6}{|l|}{ Rheumatological disease ${ }^{b}$} \\
\hline No & $68(81 \%)$ & & & & \\
\hline Yes & $16(19 \%)$ & $1,9(1,1-3,4)$ & 0,031 & $1,7(0,9-3,2)$ & 0,077 \\
\hline \multicolumn{6}{|c|}{$\begin{array}{l}\text { SSSI (superficial surgical site infection), ASA (American Society of Anaesthesiologists), } \mathrm{Cl} \text { (confidenc } \\
\text { interval) }\end{array}$} \\
\hline \multicolumn{6}{|l|}{${ }^{a}$ missing data in 1 case } \\
\hline $\mathrm{b}$ missing data in 6 cases & & & & & \\
\hline
\end{tabular}

\section{Risk factors for $P J I$}

Risk factors with a significant crude RR for development of PJI were knee surgery, ASA-class $\geq 3$ and BMI $\geq 35$. Factors found with significant adjusted RR of PJI were; knee surgery; 2,6 ( $95 \%$ Cl: 1,1-6,4), ASAclass $\geq 33,2$ (95\% Cl: $1,3-7,9), \mathrm{BMI} \geq 353,0$ (95\% Cl: $(1,2-4,2)$ and male gender $3,0(95 \% \mathrm{Cl}: 1,2-7,5)$ (Table 4). 
Table 4

Risk ratio (RR) for PJI

\begin{tabular}{|c|c|c|c|c|c|}
\hline No PJI & $\begin{array}{l}1267 \\
(98,1 \%)\end{array}$ & & & & \\
\hline PJI & $24(1,9 \%)$ & & & & \\
\hline Variable & PJI & $\begin{array}{l}\text { Crude RR } \\
(95 \% \mathrm{Cl})\end{array}$ & $\begin{array}{l}\mathrm{P}- \\
\text { value }\end{array}$ & $\begin{array}{l}\text { Adjusted RR (95\% } \\
\text { Cl) }\end{array}$ & $\begin{array}{l}\mathrm{P} \text { - } \\
\text { value }\end{array}$ \\
\hline \multicolumn{6}{|l|}{ Joint } \\
\hline Hip & $9(38 \%)$ & & & & \\
\hline Knee & $15(63 \%)$ & $2,9(1,3-6,7)$ & 0,012 & $2,6(1,1-6,4)$ & 0,033 \\
\hline \multicolumn{6}{|l|}{ Age } \\
\hline$<65$ & $12(50 \%)$ & & & & \\
\hline$\geq 65$ & $12(50 \%)$ & $1,3(0,6-2,9)$ & 0,520 & $1,0(0,4-2,5)$ & 0,941 \\
\hline \multicolumn{6}{|c|}{ ASA class } \\
\hline$\leq 2$ & $12(50 \%)$ & & & & \\
\hline$\geq 3$ & $12(50 \%)$ & $\begin{array}{l}4,9(2,2- \\
11,0)\end{array}$ & 0,000 & $3,2(1,3-7,9)$ & 0,010 \\
\hline \multicolumn{6}{|c|}{ Body Mass Index } \\
\hline$<35$ & $17(71 \%)$ & & & & \\
\hline$\geq 35$ & $7(29 \%)$ & $3,8(1,5-9,3)$ & 0,004 & $3,0(1,2-4,2)$ & 0,032 \\
\hline \multicolumn{6}{|l|}{ Gender } \\
\hline Woman & $9(38 \%)$ & & & & \\
\hline Men & $15(62 \%)$ & $2,2(0,9-5,1)$ & 0,063 & $3,0(1,2-7,5)$ & 0,016 \\
\hline \multicolumn{6}{|l|}{ Smoking } \\
\hline No & $23(96 \%)$ & & & & \\
\hline Yes & $1(4 \%)$ & $0,4(0,1-2,8)$ & 0,345 & $2,2(0,3-16,8)$ & 0,448 \\
\hline \multicolumn{6}{|l|}{ Diabetes } \\
\hline No & $19(79 \%)$ & & & & \\
\hline
\end{tabular}

SSSI (superficial surgical site infection), PJI (periprosthetic joint infection), ASA (American Society of Anaesthesiologists)

$\mathrm{Cl}$ (confidence interval) 


\begin{tabular}{|c|c|c|c|c|c|}
\hline No PJI & $\begin{array}{l}1267 \\
(98,1 \%)\end{array}$ & & & & \\
\hline Yes & $5(21 \%)$ & $2,4(0,9-6,6)$ & 0,086 & $1,4(0,5-4,0)$ & 0,544 \\
\hline \multicolumn{6}{|c|}{$\begin{array}{l}\text { Rheumatological } \\
\text { disease }\end{array}$} \\
\hline No & $19(79 \%)$ & & & & \\
\hline Yes & $5(21 \%)$ & $2,0(0,7-5,5)$ & 0,166 & $1,9(0,6-5,5)$ & 0,259 \\
\hline \multicolumn{6}{|c|}{ Table 5. Risk ratio (RR) for PJI in patients with SSSI } \\
\hline SSSI - no PJI & $66(73 \%)$ & & & & \\
\hline SSSI - PJI & $24(27 \%)$ & & & & \\
\hline Variable & PJI & $\begin{array}{l}\text { Crude RR } \\
(95 \% \mathrm{Cl})\end{array}$ & $\begin{array}{l}\mathrm{P} \text { - } \\
\text { value }\end{array}$ & $\begin{array}{l}\text { Adjusted RR } \\
(95 \% \mathrm{Cl})\end{array}$ & $\begin{array}{l}\mathrm{P} \text { - } \\
\text { value }\end{array}$ \\
\hline \multicolumn{6}{|l|}{ Joint } \\
\hline Hip & $9(37 \%)$ & & & & \\
\hline Knee & $15(63 \%)$ & $1,6(0,6-4,1$ & 0,357 & $1,5(0,5-4,4)$ & 0,462 \\
\hline \multicolumn{6}{|l|}{ Age } \\
\hline$<65$ & $12(50 \%)$ & & & & \\
\hline$\geq 65$ & $12(50 \%)$ & $1,4(0,5-3,5)$ & 0,523 & $1,6(0,6-4,9)$ & 0,376 \\
\hline \multicolumn{6}{|l|}{ ASA-class } \\
\hline$\leq 2$ & $12(50 \%)$ & & & & \\
\hline$\geq 3$ & $12(50 \%)$ & $3,0(1,1-8,2)$ & 0,025 & $3,1(1,0-10,0)$ & 0,051 \\
\hline \multicolumn{6}{|c|}{ Body Mass Index } \\
\hline$<35$ & 17 (71\%) & & & & \\
\hline$\geq 35$ & $7(29 \%)$ & $2,1(0,7-6,1)$ & 0,195 & $2,0(0,5-8,1)$ & 0,316 \\
\hline \multicolumn{6}{|l|}{ Gender } \\
\hline Woman & $9(37 \%)$ & & & & \\
\hline Men & $15(63 \%)$ & $2,6(1,0-6,7)$ & 0,055 & $3,3(1,1-10,5)$ & 0,041 \\
\hline
\end{tabular}

SSSI (superficial surgical site infection), PJI (periprosthetic joint infection), ASA (American Society of Anaesthesiologists)

$\mathrm{Cl}$ (confidence interval) 


\begin{tabular}{|c|c|c|c|c|c|}
\hline No PJI & \multicolumn{5}{|l|}{$\begin{array}{l}1267 \\
(98,1 \%)\end{array}$} \\
\hline \multicolumn{6}{|l|}{ Smoking } \\
\hline No & \multicolumn{5}{|l|}{$23(96 \%)$} \\
\hline Yes & $1(4 \%)$ & $\begin{array}{l}3,2(0,4- \\
27,0)\end{array}$ & 0,282 & $0,3(0,4-39,5)$ & 0,230 \\
\hline \multicolumn{6}{|l|}{ Diabetes } \\
\hline No & \multicolumn{5}{|l|}{$19(79 \%)$} \\
\hline Yes & $5(21 \%)$ & $1,9(0,6-6,4)$ & 0,317 & $1,6(0,3-7,5)$ & 0,556 \\
\hline \multicolumn{6}{|l|}{ Rheumatological disease } \\
\hline No & \multicolumn{5}{|l|}{$19(79 \%)$} \\
\hline Yes & $5(21 \%)$ & $0,9(0,3-2,8)$ & 0,792 & $1,2(0,3-5,1)$ & 0,780 \\
\hline \multicolumn{6}{|c|}{$\begin{array}{l}\text { SSSI (superficial surgical site infection), PJI (periprosthetic joint infection), ASA (American Society of } \\
\text { Anaesthesiologists) }\end{array}$} \\
\hline \multicolumn{6}{|l|}{ Cl (confidence interval) } \\
\hline \multicolumn{6}{|c|}{$\begin{array}{l}\text { SSSI (superficial surgical site infection), PJI (periprosthetic joint infection), ASA (American Society of } \\
\text { Anaesthesiologists) }\end{array}$} \\
\hline $\mathrm{Cl}$ (confidence interval) & & & & & \\
\hline
\end{tabular}

\section{Risk factors for PJI in patients with SSSI}

In the group of patients with SSSI, the only factor found as a significant risk factor for the progress from SSSI to PJI was male gender with an adjusted RR of 3,3 (95\% Cl: 1,1-10,5) (Table 5).

Table 5. Risk ratio (RR) for PJI in patients with SSSI 


$\begin{array}{ll}\text { SSSI - no PJI } & 66(73 \%) \\ \text { SSSI - PJI } & 24(27 \%)\end{array}$

$\begin{array}{lllll}\text { Variable } & \text { PJI } & \text { Crude RR } & \text { P-value } & \text { Adjusted RR } \\ (95 \% \mathrm{Cl}) & \text { P-value } \\ & & (95 \% \mathrm{Cl}) & \end{array}$

Joint

Hip $\quad 9(37 \%)$

Knee $\quad 15(63 \%) \quad 1,6(0,6-4,1 \quad 0,357 \quad 1,5(0,5-4,4) \quad 0,462$

Age

$<65 \quad 12(50 \%)$

$\begin{array}{llllll}\geq 65 & 12(50 \%) & 1,4(0,5-3,5) & 0,523 & 1,6(0,6-4,9) & 0,376\end{array}$

ASA-class

$\leq 2 \quad 12(50 \%)$

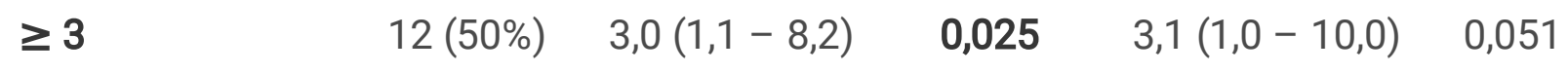

Body Mass Index

$\begin{array}{llllll}<35 & 17(71 \%) & & & \\ \geq 35 & 7(29 \%) & 2,1(0,7-6,1) & 0,195 & 2,0(0,5-8,1) & 0,316\end{array}$

Gender

Woman $\quad 9(37 \%)$

Men $\quad 15(63 \%) \quad 2,6(1,0-6,7) \quad 0,055 \quad 3,3(1,1-10,5) \quad \mathbf{0 , 0 4 1}$

Smoking

\begin{tabular}{llllll} 
No & $23(96 \%)$ & & & \\
\hline Yes & $1(4 \%)$ & $3,2(0,4-27,0)$ & 0,282 & $0,3(0,4-39,5)$ & 0,230 \\
\hline Diabetes & & & & & \\
No & $19(79 \%)$ & & & & \\
Yes & $5(21 \%)$ & $1,9(0,6-6,4)$ & 0,317 & $1,6(0,3-7,5)$ & 0,556
\end{tabular}

Rheumatological disease 


\begin{tabular}{|llllll|}
\hline No & $19(79 \%)$ & & & \\
Yes & $5(21 \%)$ & $0,9(0,3-2,8)$ & 0,792 & $1,2(0,3-5,1)$ & 0,780 \\
\hline
\end{tabular}

SSSI (superficial surgical site infection), PJI (periprosthetic joint infection), ASA (American Society of Anaesthesiologists)

$\mathrm{Cl}$ (confidence interval)

\section{Discussion}

Our work on the correlation between patient-related risk factors and SSSI or PJI includes a large cohort of primary hip and knee arthroplasties, with careful follow-up of each included patient. This study shows knee surgery, age over 65, high ASA and high BMI as independent and significant risk factors for developing SSSI or PJI.

The occurrence of SSSI may increase the risk of subsequent PJI by up to 35 times (9). If it is possible to identify high risk patients in order to optimise or even avoid patient-related risk factors preoperatively, we may be able to decrease the risk of subsequent PJI. Superficial wound complications are associated with patient morbidity and higher costs to the health-care system due to prolonged hospital stay, re-admission, ongoing treatments, and reduced patient satisfaction $(9,26,27)$. The rate of SSSI $(7 \%)$ and PJI $(1,9 \%)$ shown in this study is consistent with international studies showing levels of SSSI ranging from $1 \%$ to $10 \%(7,28)$ and PJI ranging from $0.2 \%$ to $2.23 \%(11,12,14)$.

The results in this current study where knee surgery was found to be a statistically significant risk factor for SSSI and PJI are in line with results from earlier studies, i.e. a meta-analysis including 2,000,000 patients (37 studies) by Resende et al. (29). Patients with knee prostheses have shown a higher rate of PJI and are known to be in greater need of revision surgery than patients with hip prostheses $(12,15,18$, 29). There is less soft tissue around the knee than around the hip, which means a shorter distance between skin and joint. Blood circulation around the knee area is more exposed to impact as opposed to around the hip area, and the perfusion is easier to disturb.

Age was also found to be a significant risk factor for $\mathrm{SSSI}$, which is congruent with results from a retrospective study by Carroll et al., including 1,000 patients (7). It would be reasonable to assume that an elderly patient has pre-existing medical conditions and fragile skin that can impair wound healing and cause SSSI.

A high ASA class was shown to be a significant risk factor for SSSI in univariate analysis but not shown significant after adjustment for the other covariates. The correlation between a high ASA class and SSSI may be explained by the fact that ASA class encapsulates several other known risk factors including smoking, DM, and obesity. Each of these, on their own, have been associated with a higher risk of surgical site infection as a result of tissue hypoperfusion and subsequent impaired immunological function (19, 
30). All of these factors may harm wound healing and skin perfusion. Skin impairment may lead to an SSSI, and skin perfusion must be kept robust to avoid wound complications (31).

Excess weight is generally a worrying factor, since obesity increases the risk of osteoarthritis, TJA and PJI (32). Multiple medical comorbidities, including DM type II, hypertension and cardiovascular diseases, are usually associated with obesity which consequently affects patients' BMI and ASA class (33-35). In this study, BMI $\geq 35$ was found to be a risk factor for SSSI and PJI. The association between BMI and postoperative wound complications may be explained by the need for a longer surgical incision, the increased risk of fat necrosis, prolonged or more complicated arthroplasty surgery (36), and prolonged postoperative wound drainage (37). The results in this current study are in line with large register-based studies, such as the study by Sayed-Noor et al. on 83,000 patients where the risk of re-operation within 2 to 5 years was shown to be increased for patients with higher BMI class (I-III) (38) and a study by Shohat et al. on 19,000 patients investigating the BMI cut-off threshold for association with an increased risk for PJI (39). No threshold for PJI was found (39) however a higher BMI class showed an increased risk of PJI.

Our study found male gender to be a risk factor for the progression of SSSI into PJI. In the meta-analysis by Resende et al. (29) male gender was found to be a risk factor for PJI and a subgroup analysis suggested that males were at greater risk of developing PJI, especially after TKA (29). This correlation may be attributed to some contributory behavioural factors such as smoking, diet, hygiene and alcohol consumption, but the reasons behind this are not clear. Gender-related differences in immune response due to bacteria such as Staphylococcus aureus and Pseudomonas aeruginosa are shown and septicaemia and bacteraemia are shown to occur more frequently in males than females (40) but whether or not this affects the development of SSSI or PJI has yet to be investigated.

Two of the main strengths of this study are the size of the cohort and the careful follow-up of each patient. This meticulous post-operative follow-up confirms that the number of recorded incidents of SSSI are accurate, and the follow-up time of five years, highlights any potential cases of PJI. Similar studies present a larger cohort but are based on registers only $(41,42)$ or have a shorter follow-up time $(7,8,41)$. This study exclusively includes patients with primary elective joint surgery to minimise the influence of other risk factors concatenated with the initial trauma (hip fractures) or extended impact on the tissue (revision surgery). This is an additional strength to this study since the rate of PJI is known to be higher after trauma and revision surgery (43).

A potential limitation of this study lies in the fact that this is a retrospective study design and therefore it is possible that there may be inaccuracies or a degree of misinterpretation of information received from medical records. Another limitation is that SSSI is not culture-verified but determined by a medical assessment, which however reflects the clinical reality. An additional weakness of this study is that not all factors related to wound healing could be accounted for, such as nutrition, hygiene and wound care. This information was particularly difficult to obtain once patients had been discharged from the hospital. As in infection-related research in general, where the small number of infections is a well-known challenge, this study may have missed out on the correlation between a risk factor and postoperative infection, due to a 
statistical type II error. Though this cohort is large enough to represent the average number of elective hip and knee prostheses performed in a common hospital, but an even larger cohort would have been desirable.

\section{Conclusion}

In conclusion, this study indicates that older male patients with high BMI or high ASA class should be carefully selected for TJA, especially when considered for TKA, due to the higher risk for infection. Arthroplasty surgery entails the improved quality of life and health benefit for patients. It is essential to seize any possibility to optimise all prerequisites for the best achievable surgical outcome.

\section{Abbreviations}

Superficial surgical site infection: SSSI; Periprosthetic joint infection: PJl; Total Joint Arthroplasty: TJA; Total Hip Arthroplasty: THA; Total Knee Arthroplasty: TKA; Body Mass Index: American Society of Anaesthesiologists classification: ASA class; BMI; Rheumatological disease: RA; Diabetes Mellitus: DM.

\section{Declarations}

\section{Ethics approval}

The study design was reviewed and approved by the Human Research Ethics Committee in Uppsala, Sweden, Dnr: 2019-01425.

\section{Consent for publication}

Consent for publication was considered in the application to the Human Research Ethics Committee. However, no consent, verbal or written was needed, due to the retrospective study design. The application and decision (Dnr: 2019-01425) are available from the corresponding author upon request.

\section{Availability of data and materials}

The dataset generated and analysed during the current study are available from the corresponding author on reasonable request.

\section{Competing interests}

The authors declare that they have no competing interests in this work.

\section{Funding}

There was no funding of this study.

\section{Authors' contributions}


Both authors (HE, SL) made substantial contributions to conception and design of the study and in acquisition, analysis and interpretation of data. Both authors (HE, SL) have been involved in drafting the manuscript and given final approval of the version to be published. Both authors (HE, SL) have participated sufficiently in the work to take public responsibility for appropriate portions of the content and agreed to be accountable for all aspects of the work in ensuring that questions related to the accuracy or integrity of any part of the work are appropriately investigated and resolved.

\section{Acknowledgements}

We thank Jakob Viklander for his valuable assistance during data compilation.

\section{References}

1. Kurtz SM, Lau E, Schmier J, Ong KL, Zhao K, Parvizi J. Infection burden for hip and knee arthroplasty in the United States. J Arthroplasty. 2008;23(7):984-91.

2. Kurtz SM, Ong KL, Lau E, Bozic KJ, Berry D, Parvizi J. Prosthetic joint infection risk after TKA in the Medicare population. Clin Orthop Relat Res. 2010;468(1):52-6.

3. Gundtoft PH, Pedersen AB, Varnum C, Overgaard S. Increased Mortality After Prosthetic Joint Infection in Primary THA. Clin Orthop Relat Res. 2017;475(11):2623-31.

4. Gundtoft PH, Pedersen AB, Schønheyder HC, Møller JK, Overgaard S. One-year incidence of prosthetic joint infection in total hip arthroplasty: a cohort study with linkage of the Danish Hip Arthroplasty Register and Danish Microbiology Databases. Osteoarthritis Cartilage. 2017;25(5):685-93.

5. Kurtz SM, Lau EC, Son MS, Chang ET, Zimmerli W, Parvizi J. Are We Winning or Losing the Battle With Periprosthetic Joint Infection: Trends in Periprosthetic Joint Infection and Mortality Risk for the Medicare Population. J Arthroplasty. 2018;33(10):3238-45.

6. Galat DD, McGovern SC, Larson DR, Harrington JR, Hanssen AD, Clarke HD. Surgical treatment of early wound complications following primary total knee arthroplasty. J Bone Joint Surg Am. 2009;91(1):48-54.

7. Carroll K, Dowsey M, Choong P, Peel T. Risk factors for superficial wound complications in hip and knee arthroplasty. Clin Microbiol Infect. 2014;20(2):130-5.

8. Peersman G, Laskin R, Davis J, Peterson M. Infection in total knee replacement: a retrospective review of 6489 total knee replacements. Clin Orthop Relat Res. 2001(392):15-23.

9. Saleh K, Olson M, Resig S, Bershadsky B, Kuskowski M, Gioe T, et al. Predictors of wound infection in hip and knee joint replacement: results from a 20 year surveillance program. J Orthop Res. 2002;20(3):506-15.

10. Lima AL, Oliveira PR, Carvalho VC, Saconi ES, Cabrita HB, Rodrigues MB. Periprosthetic Joint Infections. Interdiscip Perspect Infect Dis. 2013;2013:542796. 
11. Urquhart DM, Hanna FS, Brennan SL, Wluka AE, Leder K, Cameron PA, et al. Incidence and risk factors for deep surgical site infection after primary total hip arthroplasty: a systematic review. $J$ Arthroplasty. 2010;25(8):1216-22.e1-3.

12. Ridgeway S, Wilson J, Charlet A, Kafatos G, Pearson A, Coello R. Infection of the surgical site after arthroplasty of the hip. J Bone Joint Surg Br. 2005;87(6):844-50.

13. Cooper K, Lamagni T, Harrington P, Wloch $C$, Hopkins S. Surveillance of surgical site infections in NHS hospitals in England, April 2018 to March 2019. Available from: www.gov.uk/phe. Accessed: 15 May 2020.

14. Phillips JE, Crane TP, Noy M, Elliott TS, Grimer RJ. The incidence of deep prosthetic infections in a specialist orthopaedic hospital: a 15-year prospective survey. J Bone Joint Surg Br. 2006;88(7):943-8.

15. Pulido L, Ghanem E, Joshi A, Purtill JJ, Parvizi J. Periprosthetic joint infection: the incidence, timing, and predisposing factors. Clin Orthop Relat Res. 2008;466(7):1710-5.

16. Jämsen $E$, Varonen M, Huhtala H, Lehto MU, Lumio J, Konttinen YT, et al. Incidence of prosthetic joint infections after primary knee arthroplasty. J Arthroplasty. 2010;25(1):87-92.

17. Dale H, Fenstad AM, Hallan G, Havelin LI, Furnes O, Overgaard S, et al. Increasing risk of prosthetic joint infection after total hip arthroplasty. Acta Orthop. 2012;83(5):449-58.

18. Kong L, Cao J, Zhang Y, Ding W, Shen Y. Risk factors for periprosthetic joint infection following primary total hip or knee arthroplasty: a meta-analysis. Int Wound J. 2017;14(3):529-36.

19. Kunutsor SK, Whitehouse MR, Blom AW, Beswick AD, Team I. Patient-Related Risk Factors for Periprosthetic Joint Infection after Total Joint Arthroplasty: A Systematic Review and Meta-Analysis. PLoS One. 2016;11(3):e0150866.

20. Maoz G, Phillips M, Bosco J, Slover J, Stachel A, Inneh I, et al. The Otto Aufranc Award: Modifiable versus nonmodifiable risk factors for infection after hip arthroplasty. Clin Orthop Relat Res. 2015;473(2):453-9.

21. Everhart JS, Altneu E, Calhoun JH. Medical comorbidities are independent preoperative risk factors for surgical infection after total joint arthroplasty. Clin Orthop Relat Res. 2013;471(10):3112-9.

22. Schrama JC, Espehaug B, Hallan G, Engesaeter LB, Furnes O, Havelin LI, et al. Risk of revision for infection in primary total hip and knee arthroplasty in patients with rheumatoid arthritis compared with osteoarthritis: a prospective, population-based study on 108,786 hip and knee joint arthroplasties from the Norwegian Arthroplasty Register. Arthritis Care Res (Hoboken). 2010;62(4):473-9.

23. Höftprotesregistret S. Svenska Höftprotesregistret 2019 [Annual report.]. Available from: www.shpr.se. Accessed: 15 May 2020. 
24. Swedish Association of Local Authorities and Regions. 2020. Available from: www.skr.se. Accessed: 15 May 2020.

25. Parvizi J, Zmistowski B, Berbari EF, Bauer TW, Springer BD, Della Valle CJ, et al. New Definition for Periprosthetic Joint Infection: From the Workgroup of the Musculoskeletal Infection Society. Clin Orthop Relat Res. 4692011. p. 2992-4.

26. Smith TO, Sexton D, Mann C, Donell S. Sutures versus staples for skin closure in orthopaedic surgery: meta-analysis. BMJ. 2010;340:c1199.

27. Berbari EF, Hanssen AD, Duffy MC, Steckelberg JM, Ilstrup DM, Harmsen WS, et al. Risk factors for prosthetic joint infection: case-control study. Clin Infect Dis. 1998;27(5):1247-54.

28. Guirro P, Hinarejos P, Pelfort X, Leal-Blanquet J, Torres-Claramunt R, Puig-Verdie L. Long term followup of successfully treated superficial wound infections following TKA. J Arthroplasty. 2015;30(1):101-3.

29. Resende VAC, Neto AC, Nunes C, Andrade R, Espregueira-Mendes J, Lopes S. Higher age, female gender, osteoarthritis and blood transfusion protect against periprosthetic joint infection in total hip or knee arthroplasties: a systematic review and meta-analysis. Knee Surg Sports Traumatol Arthrosc. 2018.

30. Anaya DA, Dellinger EP. The obese surgical patient: a susceptible host for infection. Surg Infect (Larchmt). 2006;7(5):473-80.

31. Ries MD. Skin necrosis after total knee arthroplasty. J Arthroplasty. 2002;17(4 Suppl 1):74-7.

32. Yayac M, Aggarwal R, Parvizi J. How viable is pre-surgery weight reduction for the reduction of periprosthetic joint infection risk after total joint arthroplasty? Expert Rev Med Devices. 2020;17(3):149-51.

33. Hartemink N, Boshuizen HC, Nagelkerke NJ, Jacobs MA, van Houwelingen HC. Combining risk estimates from observational studies with different exposure cutpoints: a meta-analysis on body mass index and diabetes type 2. Am J Epidemiol. 2006;163(11):1042-52.

34. Khaodhiar L, McCowen KC, Blackburn GL. Obesity and its comorbid conditions. Clin Cornerstone. 1999;2(3):17-31.

35. Guh DP, Zhang W, Bansback N, Amarsi Z, Birmingham CL, Anis AH. The incidence of co-morbidities related to obesity and overweight: a systematic review and meta-analysis. BMC Public Health. 2009;9:88.

36. Dowsey MM, Choong PF. Obesity is a major risk factor for prosthetic infection after primary hip arthroplasty. Clin Orthop Relat Res. 2008;466(1):153-8. 
37. Patel VP, Walsh M, Sehgal B, Preston C, DeWal H, Di Cesare PE. Factors associated with prolonged wound drainage after primary total hip and knee arthroplasty. J Bone Joint Surg Am. 2007;89(1):338.

38. Sayed-Noor AS, Mukka S, Mohaddes M, Kärrholm J, Rolfson O. Body mass index is associated with risk of reoperation and revision after primary total hip arthroplasty: a study of the Swedish Hip Arthroplasty Register including 83,146 patients. Acta Orthop. 2019;90(3):220-5.

39. Shohat N, Fleischman A, Tarabichi M, Tan TL, Parvizi J. Weighing in on Body Mass Index and Infection After Total Joint Arthroplasty: Is There Evidence for a Body Mass Index Threshold? Clin Orthop Relat Res. 2018;476(10):1964-9.

40. McClelland EE, Smith JM. Gender specific differences in the immune response to infection. Arch Immunol Ther Exp (Warsz). 2011;59(3):203-13.

41. Almustafa MA, Ewen AM, Deakin AH, Picard F, Clarke JV, Mahmood FF. Risk Factors for Surgical Site Infection Following Lower Limb Arthroplasty: A Retrospective Cohort Analysis of 3932 Lower Limb Arthroplasty Procedures in a High Volume Arthroplasty Unit. J Arthroplasty. 2018;33(6):1861-7.

42. Jämsen E, Huhtala H, Puolakka T, Moilanen T. Risk factors for infection after knee arthroplasty. A register-based analysis of 43,149 cases. J Bone Joint Surg Am. 2009;91(1):38-47.

43. Kärrholm J, Rogmark C, Nauclér E, Vinblad J, Mohaddes M, Rolfson R. Swedish Hip Arthroplasty Register. [Annual report 2018]. Available from: www.shpr.se. Accessed: 2 May 2020.

\section{Figures}




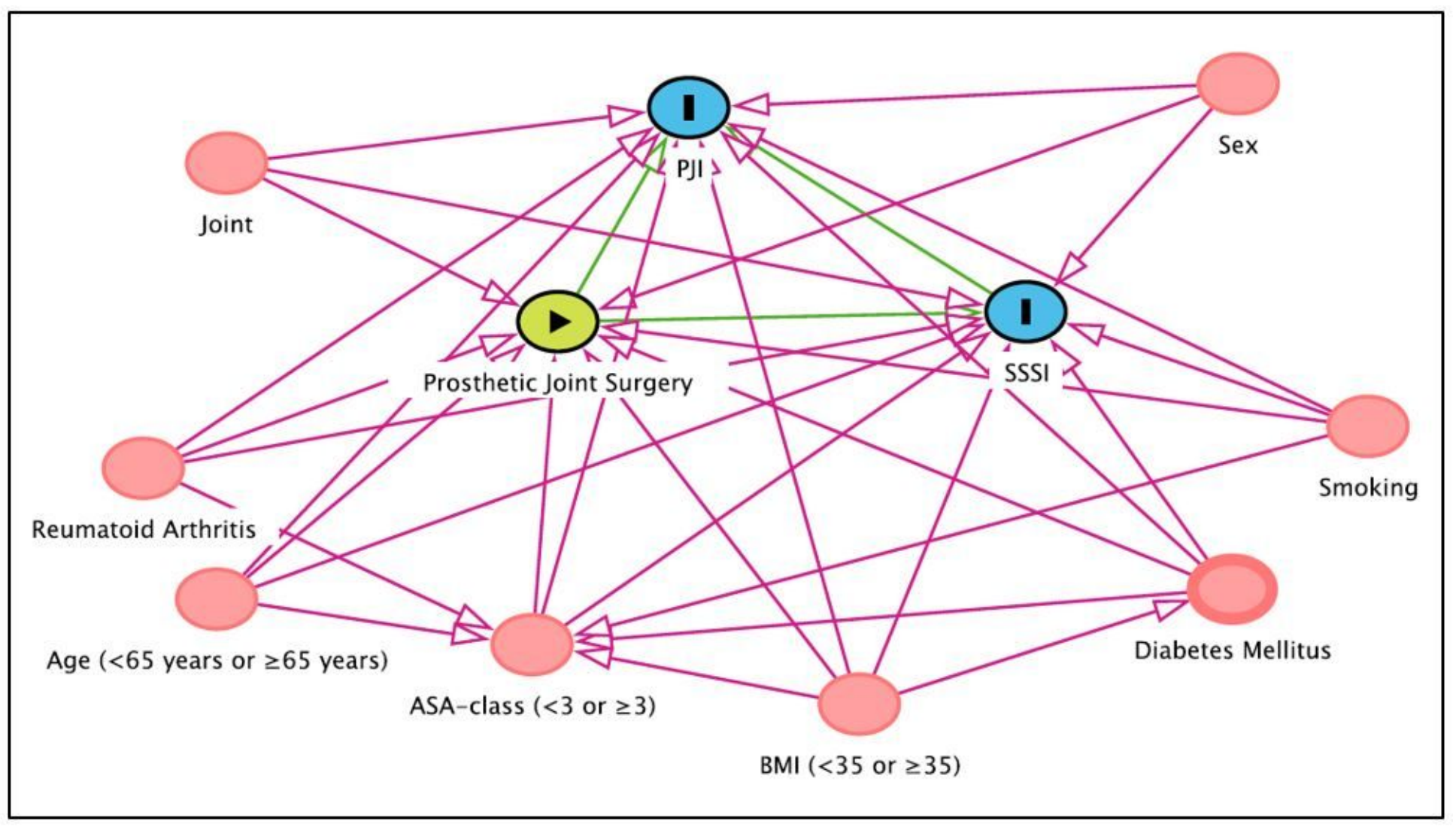

Figure 1

Directed Acyclic Graph (DAG) used to select confounders. The green circle indicates the exposure. Blue circles illustrate outcomes. Red circles indicate confounders used in the statistical model. 